\title{
Anesthetic Management of an Ankylosing Spondylitis Patient with Normal Pressure Hydrocephalus for the Ventriculoperitoneal Shunt
}

\author{
Sakshi Thakore ${ }^{1, \odot ~ V a r u n ~ J a i n ~}{ }^{2, \odot} \quad$ Mukesh Gupta $^{2}$
}

Address for correspondence Varun Jain, MBBS, MD, DNB, DM, Department of Neuroanesthesia, Paras Hospital, Gurgaon 122002, Haryana, India (e-mail: varunj2202@gmail.com).

J Neuroanaesthesiol Crit Care 2021;8:228-229.

Ankylosing spondylitis (AS) poses unique challenges to anesthesiologists owing to difficult airway and cardiorespiratory compromise. ${ }^{1-3}$ We describe the anesthetic management of a case of AS with normal pressure hydrocephalus (NPH) for lumbar puncture (LP) followed by ventriculoperitoneal shunt (VPS) surgery.

A 68-year-old male weighing $65 \mathrm{~kg}$, case of AS for 25 years, American Society of Anesthesiologists (ASA) grade III presented with gradually progressive slowness of gait and urinary incontinence for 5 months. Computed tomography scan of head was suggestive of hydrocephalus. Magnetic resonance imaging cervical spine revealed ankylosis of cervical vertebrae with arthrosis of the atlantoaxial joint ( - Fig. 1). LP was performed in left lateral position with limited hip and knee flexion. $40 \mathrm{~mL}$ cerebrospinal fluid (CSF) was drained at a pressure of $12 \mathrm{~mm} \mathrm{Hg}$. Patient showed significant improvement in gait
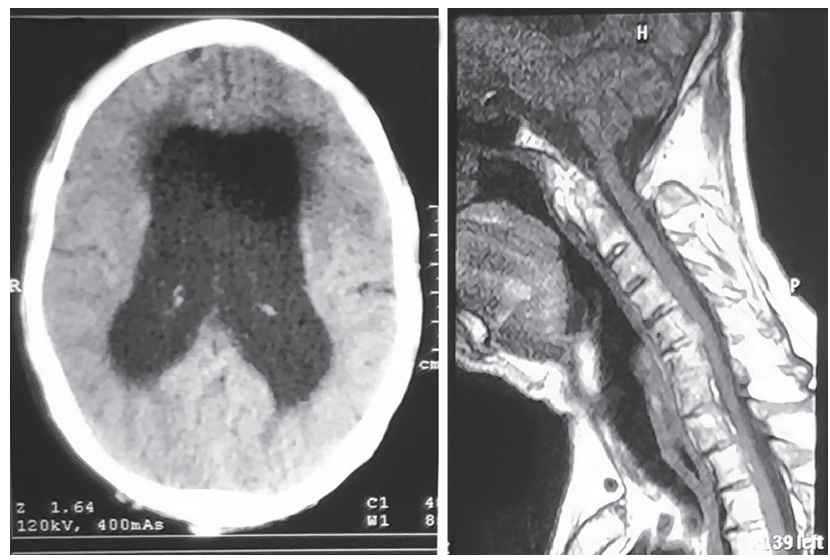

Fig. 1 Left side: Noncontrast computed tomography (NCCT) head (axial cut) showing hydrocephalus. Right side: Magnetic resonance imaging (MRI) cervical spine ( $\mathrm{T} 1$ sequence sagittal) showing ossified vertebral column.

published online

December 3, 2020
DoI https://doi.org/

10.1055/s-0040-1719227 ISSN 2348-0548. and a diagnosis of NPH was established. He was then posted for VPS the next day. Preanesthetic evaluation of the airway revealed restricted mouth opening $(2 \mathrm{~cm})$, Mallampati class IV, fixed flexion deformity of neck, and loss of cervical and lumbar lordosis. Breath holding time was 20 seconds and pulmonary function test revealed severe restrictive lung disease (forced expiratory volume in 1 second [FEV1] 34\%, forced vital capacity [FVC] 33\%, FEV1/FVC 101\%). Risks of anesthesia pertaining to difficult airway and perioperative pulmonary complications were explained and consent for anesthesia was obtained, but patient refused for awake fiberoptic bronchoscopic (FOB) intubation. He was taught deep breathing exercises (DBE) and incentive spirometry (IS).

On the day of surgery, standard ASA monitoring was applied and a stack of pillows and gel-ring were placed under the head and neck in Trendelenburg position ( - Fig. 2). After preoxygenation with $100 \%$ oxygen for 5 minutes, induction was done with $100 \mathrm{mcg}$ fentanyl and $20 \mathrm{mg}$ graded boluses (total $60 \mathrm{mg}$ ) of propofol to preserve spontaneous breathing. However, breathing became shallow and jerky due to backward falling of tongue and airway obstruction. Bag mask ventilation (BMV) was inadequate with nasopharyngeal airway (NPA) (size 8.0) but became possible with oropharyngeal airway (OPA). Due to failed attempt through oral FOB, plan was changed to nasal FOB. Glottic opening could be visualized only after pulling the tongue anteriorly and 7.5 $\mathrm{mm}$ endotracheal tube was advanced under vision into the trachea. Anesthesia was maintained with oxygen, air, desflurane, and atracurium. Because of nonmaneuverability of the neck, conventional surgical position with neck rotation was not possible and shunt was manipulated from the cranial burr (Kocher's point) in three passes. Patient was shifted to intensive care unit postoperatively. After the reversal of neuromuscular blockade, he was extubated when fully awake, obeying commands with adequate spontaneous respiratory

(C) 2020. Indian Society of Neuroanaesthesiology and Critical Care. This is an open access article published by Thieme under the terms of the Creative Commons Attribution-NonDerivative-NonCommercial-License, permitting copying and reproduction so long as the original work is given appropriate credit. Contents may not be used for commercial purposes, or adapted, remixed, transformed or built upon. (https://creativecommons.org/licenses/by-nc-nd/4.0/)

Thieme Medical and Scientific Publishers Pvt. Ltd., A-12, 2nd Floor, Sector 2, Noida-201301 UP, India 


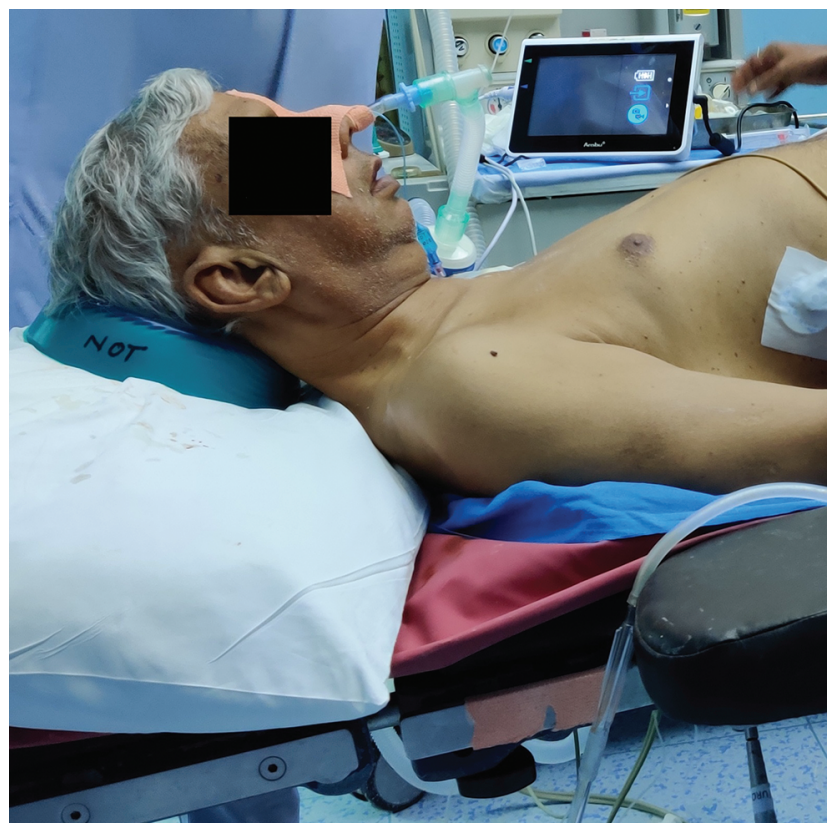

Fig. 2 Patient positioning (head low with pillows) to support head in fixed flexion deformity.

efforts. DBE and IS were continued in the postoperative period. He was discharged on second postoperative day and was doing well with improvement in symptoms at 2 weeks' follow-up.

\section{Discussion}

Anesthetic challenges in management of the rare cooccurrence of AS with NPH has not been reported, and is probably the first case in literature., ${ }^{2,3}$ It imposed array of difficulties ranging from technically difficult LP, airway hazards, and positioning issues.

Fibrosis of the spine made LP more complicated. One interesting finding in our case was difficulty in ventilation with NPA but not with OPA. This could be due to the malleable nature of NPA, and larger nares to epiglottis distance. It indicates that a standard size NPA can be shorter in case of fixed flexion deformity of neck. Direct and video laryngoscopy was not possible due to shaft getting struck to the chest and misalignment of oropharyngeal axis with laryngeal axis. Oral FOB was unsuccessful because of decreased oropharyngeal space and more acute angulation in approaching glottis via oral route, therefore nasal FOB was the better choice. ${ }^{4}$ Lingual traction maneuver helped us in negotiation of FOB. Other airway supporting maneuvers like head tilt, chin lift, and jaw thrust were not possible because of probable ankylosis of the temporomandibular joint. Lung fibrosis leading to severe restrictive lung disease gave us only limited duration of apnea without desaturation for FOB. Adequate preoxygenation and oxygen insufflation through nasopharyngeal catheter during apnea period has been shown to increase the time to desaturation. ${ }^{5}$ Careful positioning is imperative in AS because of high risk of spine fractures in osteoporotic bones. ${ }^{6,7}$ Ideal positioning for intubation and procedure was not possible in our case due to fixity of the spine. A stack of pillows below the head helped to keep the head as in preoperative position.

To conclude, management of NPH with coexisting AS has its own challenges. Performance of LP to assess beneficence of a definitive CSF diversion procedure like VPS is difficult but necessary. OPA is a better choice for BMV. Nasal FOB with lingual traction while maintaining spontaneous respiration is the appropriate technique if the consent for awake FOB is not provided. ${ }^{4}$ Restrictive lung disease and inappropriate posture add to the challenges. Preoperative lung expansion maneuvers and preparedness for the anticipated difficult airway is the key to successful management of this case.

\section{Conflict of Interest}

None declared.

\section{References}

1 Woodward LJ, Kam PCA. Ankylosing spondylitis: recent developments and anaesthetic implications. Anaesthesia 2009;64(5):540-548

2 Talikoti AT, Dinesh K, Kumar A. Goolappa. Ankylosing spondylitis: a challenge to anaesthesiologists due to difficulties in airway management and systemic involvement of disease. Indian J Anaesth 2010;54(1):70-71

3 Kumar N, Bindra A, Mahajan C, Yadav N. Airway management in a patient of ankylosing spondylitis with traumatic cervical spine injury. Saudi J Anaesth 2015;9(3):327-329

4 Tian W. The effect of anaesthesia on oral fibreoptic tracheal intubation in a patient of ankylosing spondylitis. On J Complement \& Alt Med 2020;4(5):1-3

5 Tanoubi I, Drolet P, Donati F. Optimizing preoxygenation in adults. Can J Anaesth 2009;56(6):449-466

6 Sinclair JR, Mason RA. Ankylosing spondylitis. The case for awake intubation. Anaesthesia 1984;39(1):3-11

7 Ruf M, Rehm S, Poeckler-Schoeniger C, Merk HR, Harms J. Iatrogenic fractures in ankylosing spondylitis-a report of two cases. Eur Spine J 2006;15(1):100-104 